Revista de Ciencias Sociales - Número 66 (2015) - Páginas 187-212

Una aproximación constitucional al matrimonio entre personas del mismo sexo

\title{
UNA APROXIMACIÓN CONSTITUCIONAL AL MATRIMONIO ENTRE PERSONAS DEL MISMO SEXO
}

\section{AN APPROACH CONSTITUTIONAL TO SAME-SEX MARRIAGE}

\author{
SEBASTIÁN BECKER CASTELLARO* \\ Universidad de Chile \\ sebastian.becker.castellaro@gmail.com
}

\section{Resumen}

Este trabajo trata de responder las objeciones al matrimonio entre personas del mismo sexo desde una óptica constitucional. Las justificaciones para impedirlo corresponden a argumentos centrados en el iusnaturalismo que, realizando un análisis constitucional, terminan siendo contrarios a un Estado de derecho democrático debido a que no siguen la lógica de una concepción política de persona ni tampoco un respeto irrestricto a los derechos fundamentales.

\footnotetext{
* Abogado, Universidad de Chile. Ayudante Ad-honorem, Departamento de Derecho Público, Facultad de Derecho, Universidad de Chile, Santiago de Chile. Un trabajo previo a este se expuso en las IV Jornadas Estudiantiles de Género y Derecho días 4, 5 y 6 de diciembre 2013, Santiago de Chile, Facultad de Derecho, Universidad de Chile. Artículo recibido el 28 de abril de 2015 y aceptado el 29 de mayo de 2015.
}

Revista de Ciencias Sociales - Número 66 (2015) - Universidad de Valparáíso - ISSN 0716-7725-Valparaíso, Chile 


\section{Palabras clave}

Matrimonio, derecho natural, ius conubii, Estado democrático de derecho, concepción política de persona.

\section{Abstract}

This paper tries to respond to the same sex marriage objections through a constitutional point of view. The reasons to prevent it are arguments based on iusnaturalism that are against rule of law, because they don't follow the political conception of person and they show a lack of respect of human rights.

\section{Keywords} of person.

Marriage, natural right, ius conubii, rule of law, political conception

\section{Introducción}

El normativizar espacios públicos políticos como el matrimonio implica necesariamente incorporar los derechos fundamentales para poder hacer valer la autodeterminación de los individuos en el Estado democrático de derecho. Esto porque el (Estado Democrático de) Derecho se entiende a sí mismo como un sistema de integración social, en el cual los fenómenos sociológicos y comunicativos se permean en los discursos políticos y estos, a través de procedimientos racionales y legítimos, a su vez, se permean nuevamente en el mundo del derecho, resultando un derecho dinámico, democrático y legítimo ${ }^{1}$.

Por otro lado, estudiar el derecho a través de una óptica iusnaturalista implica entender al derecho como a-histórico y sin capacidad de dinamismo, es decir, trascendental; siendo este el sentido en que han emergido los principales argumentos para poder frenar una legislación a favor del matrimonio entre personas del mismo sexo. Es

decir, las objeciones pretenden mantener un status quo a la institución del matrimonio.

1. HABERMAS, Jürgen: “Facticidad y Validez”, Madrid, Editorial Trotta, 2008. Págs. 94-95.

Facultad de Derecho y Ciencias Sociales - Universidad de Valparaíso - Chile 
Por tanto, desde la pretensión iusnaturalista habrá que analizar si es posible mantener la institución del matrimonio respetando irrestrictamente los derechos fundamentales, o es que, como señala HABERMAS $^{2}$, el derecho natural impide una visión sociointegradora del derecho y por tanto, que fluyan íntegramente los nuevos comportamientos sociales actuales en el Estado democrático de derecho.

Entonces, para partir, la definición de matrimonio se consagra en el artículo 102 del Código Civil como el contrato solemne por el cual un hombre y una mujer se unen actual e indisolublemente, por toda la vida, con el fin de vivir juntos, de procrear y auxiliarse mutuamente. Con esta definición de matrimonio, se entra a la discusión de si es posible o no un matrimonio entre personas del mismo sexo. ¿Es, factible entender al matrimonio como una institución a-histórica trascendental en el tiempo? ¿Por qué la heterosexualidad es esencial en el contrato de matrimonio? ¿Qué razones existen para que la procreación sea entendida como un elemento natural? ¿Es posible entender al matrimonio como institución natural, con la procreación como uno de sus elementos, y, a la vez, dotarlo de legitimidad a través de derechos fundamentales? Estas son parte de las preguntas que se tratarán de responder en este trabajo.

Así el trabajo se organiza de la siguiente forma: (1) Se analizará el matrimonio, con especial énfasis en el ius connubii y la idea de diversidad de sexos. (2) Luego se analizará la finalidad de la procreación dentro del matrimonio, realizando una crítica, desde una perspectiva constitucional, de cómo ésta afecta los derechos fundamentales de las personas y una construcción justa del Estado de Derecho democrático.

\section{Análisis constitucional de la naturaleza jurídica del matrimonio chileno}

En este acápite se analizará el concepto de ius connubii. La idea es interiorizarnos sobre si este (supuesto) derecho fundamental de casarse también involucra a las personas homosexuales y, si no los implica jurídicamente, explicar según qué criterios se niega tal derecho.

2. Ibíd. pág. 205

Revista de Ciencias Sociales - Número 66 (2015) - Universidad de Valparáíso - ISSN 0716-7725-Valparaíso, Chile 
En segundo término se analizará la diversidad de sexo y su relación con la naturaleza del matrimonio. Conjuntamente se analizará la inexistencia del matrimonio al ser celebrado por dos contrayentes del mismo sexo y sus implicancias en los derechos fundamentales, a la luz de la naturaleza jurídica del mismo matrimonio.

\subsection{Ius Connubii}

En el artículo 2 de la Ley de Matrimonio Civil (LMC) se consagra el ius connubii como la facultad de contraer matrimonio como un derecho esencial e inherente a la persona humana. Aquello deriva de la típica construcción contractualista del Estado liberal (Hobbes, Locke, etc.) en donde las personas son previas a éste, por lo que el Estado debe respetar ciertos derechos básicos e inherentes a la naturaleza humana como la libertad o la vida; aquí la libertad se erige en un sentido negativo, a lo Isaiah Berlin.

El concepto del ius connubii y su consagración en la LMC tiene por objeto ser entendido como un derecho de carácter constitucional debido a que lo que se está consagrando, es el reconocimiento de las personas como agentes racionales capaces de tomar decisiones sin ninguna clase de coacción. Asimismo, la libertad fundamental para las personas de contraer matrimonio es herencia de la jurisprudencia romana y del Corpus Juris Civilis que establecían el concepto conubium, que a su vez fue consagrada en el Derecho Canónico, influenciando posteriormente a nuestro ordenamiento jurídico. También en los tratados de Derechos Humanos se encuentra consagrado el ius conubii: en el artículo $16.1^{3}$ de la Declaración universal de los derechos humanos de 1948, en el artículo 6.2a $a^{4}$ de la Declaración sobre la eliminación de

3. "Los hombres y las mujeres, a partir de la edad núbil, tienen derecho, sin restricción alguna por motivos de raza, nacionalidad y religión, a casarse y fundar una familia; disfrutarán de iguales derechos en cuanto al matrimonio, durante el matrimonio y en caso de disolución del matrimonio".

4. "Deberán adoptarse todas las medidas apropiadas para asegurar el principio de la igualdad de condición del marido y de la esposa, y en particular: a) la mujer tendrá el mismo derecho que el hombre a escoger libremente cónyuge y a contraer matrimonio sólo mediante su pleno y libre consentimiento".

Facultad de Derecho y Ciencias Sociales - Universidad de Valparaíso - Chile 
la discriminación contra la mujer de 1967, y el Pacto internacional de derechos civiles y políticos de 1966 en su artículo $23.2^{5}$, consagrados, ratificados e incorporados a nuestro ordenamiento jurídico interno vía artículo 5 inciso 2 (a pesar de sus críticas).

La doctrina nacional ha entendido el ius connubii como un derecho fundamental y capaz de ejercerse de manera erga omnes, lo que no lleva, eso sí, a establecer un deber de contraer matrimonio ${ }^{6}$. En este mismo sentido es que Barrientos y Novales entienden que la idea de inherente y esencial no es sino una forma de vincularla con la idea de personas libres e iguales que consagra nuestra Constitución en las bases de la institucionalidad. Siguiendo la misma línea se manifiesta el profesor del Picó, en cuanto establece que el ius connubii es "un derecho esencial de la persona humana y no meramente una proyección de un derecho ciudadano, constituyéndose en un principio fundamental del Derecho matrimonial occidental, asentado con fuerza a contar de la segunda mitad del siglo XX. No es por tanto una concesión del legislador, sino una exigencia de justicia que la misma naturaleza humana fundamenta", que en coherencia con la doctrina en general, la reconoce como una vinculación al derecho del libre desarrollo de la personalidad humana y al interés social de la irrenunciabilidad de los derechos previos al Estado. Asimismo del Picó señala que la consagración de este derecho en la LMC es para "asegurar el consentimiento libre de los contrayentes" ${ }^{8}$, concordando con la postura de Barrientos y Novales en cuanto señalan que el ius connubii tiene dos dimensiones: una positiva, o sea, un "derecho a contraer

5. "Se reconoce el derecho del hombre y la mujer a contraer matrimonio y a fundar una familia si tienen edad para ello".

6. BARRIENTOS GRANDÓN, Javier y NOVALES ALQUÉZAR, Aránzazu: "Nuevo Derecho Matrimonial chileno", Santiago de Chile, Editorial LexisNexis, 2004. Pág. 146.

7. DEL PICÓ RUBIO, Jorge: “Derecho matrimonial Chileno”, Santiago de Chile, Abeledo Perrot Legal Publishing, 2010. Págs. 128-129.

8. Ibíd. Pág. 130.

Revista de Ciencias Sociales - Número 66 (2015) - Universidad de Valparáíso - ISSN 0716-7725-Valparáiso, Chile 
matrimonio, ausente de toda traba, embarazo, obstáculo o impedimento", y una negativa, que comprende el que se tiene derecho a no contraer matrimonio, lo que se materializa en la no existencia de coacción alguna que pretenda mover la voluntad de las personas a contraerlo. Así "la incapacidad para el ejercicio de ese derecho no puede ser circunstancial, ni neutra, ni voluntaria. Por consiguiente, debe proceder sólo en casos graves y justificados, siendo además una materia de regulación legislativa obligatoria e interpretación restrictiva" ${ }^{10}$. Esta idea también la consagra Barrientos y Novales en cuanto el derecho a contraer matrimonio estaría amparado en virtud del artículo $19 \mathrm{~N}^{\circ} 26$ de nuestra Constitución ${ }^{11}$.

Ahora, si entendemos el ius connubii como un derecho inherente a la persona humana y previo al Estado, al celebrar un contrato de matrimonio de carácter legal ¿qué razones privan a las personas homosexuales el derecho esencial a casarse? ¿Dónde está la idea de igualdad — propia también de los derechos naturales previos al Estadodel ius connubii?

La doctrina ha respondido que la institución del matrimonio, de lo que principalmente se está hablando, es un vínculo heterosexual, es decir, que el matrimonio correspondería, por su naturaleza preestatal $^{12}$, a un vínculo entre un hombre y una mujer. Es por ello, dicen

9. BARRIENTOS GRANDÓN, Javier y NOVALES ALQUÉZAR, Aránzazu: Ob. cit. Pág. 147.

10. ISLER SOTO, Erika: "Los principios de la Ley 19.947: análisis y desarrollo" [en línea] En: Ars Boni et Aequi, 2009, [consultado el 20 de abril de 2015] http://www.ubo.cl/icsyc/wp-content/uploads/2011/09/4-Isler.pdf pág. 96.

11. Véase BARRIENTOS GRANDÓN, Javier y NOVALES ALQUÉZAR, Aránzazu: Ob. cit. Pág. 151. A pesar de la desprolijidad jurídica que es establecer un derecho constitucional en una ley. Véase también ALDUNATE LIZANA, Eduardo: "El derecho esencial a contraer matrimonio", En: Vidal Olivares, Álvaro. "El nuevo Derecho chileno del Matrimonio", Santiago de Chile, Editorial Jurídica de Chile, 2006. Pág. 42.

12. Aquí la postura natural "pre-estatal” cae en una paradoja sin salida. Para que sea posible la institución del matrimonio es necesaria la consagración de un Estado que reconozca la institución misma, por tanto, en un plano de "estado natural" aquél no existe, por tanto, tampoco el matrimonio. Véase ALDUNATE LIZANA, Eduardo: Ob. cit. Págs. 45 y ss.

Facultad de Derecho y Ciencias Sociales - Universidad de Valparaíso - Chile 
por ejemplo en España, que en "el artículo $32 \mathrm{CE}$ se habla de hombre y mujer ${ }^{13}$; mención que contrasta con los términos genéricos y neutros de los ciudadanos, todas las personas o todos los españoles que por doquier aparecen en el resto del articulado" ${ }^{14}$. En el mismo sentido lo señala el autor TIRAPU: "La doctrina y la jurisprudencia, al referirse al ius connubii, como derecho fundamental de la persona humana, lo conectan con las nociones de masculinidad y feminidad, precisamente por ser el matrimonio la peculiar relación en la que el hombre emite como varón y la mujer en cuanto tal un consentimiento verdaderamente matrimonial”"15; así, el profesor, refiriéndose al artículo 32 de la Constitución española, señala:

“[E]n efecto, el hecho de que el artículo 32.1 de la Constitución proclame que 'el hombre y la mujer tienen derecho a contraer matrimonio con plena igualdad jurídica' no autoriza a concluir que al haberse omitido por cualesquiera razones la expresión entre sí, la Constitución permita el matrimonio entre personas del mismo sexo. Al contrario es muy significativo que en el Capítulo segundo del Título I de la Constitución del artículo 32, dedicado a los derechos y libertades fundamentales, el único que se preocupa de precisar que el hombre y la mujer son los titulares del ius nubendi, mientras que en todos los demás casos se utilizan formas genéricas o impersonales como 'todos', 'toda persona', 'se garantiza', 'se reconoce', 'tienen derecho', sin estimarse necesario referir el derecho al sexo concreto de la persona" ${ }^{16}$.

13. Como también en los tratados internacionales y la Ley de Matrimonio Civil.

14. ASÚA GONZÁLEZ, Clara: "Matrimonio entre personas del mismo sexo. Reflexiones al hijo de la ley 13/2005". En: "Nuevas familias y principio de igualdad: un debate abierto", San Sebastián, Jornadas de Derechos Humanos No 9, 2005. Pág. 50.

15. TIRAPU MARTÍNEZ, Daniel: "La cuestión no cerrada del matrimonio homosexual” [en línea]. En: Revista de Estudios jurídicos No 10/2010 (Segunda época) ISSN 1576-124X. Universidad de Jaén (España) [consultado 20 de abril de 2015] http://revistaselectronicas.ujaen.es/index.php/rej/article/view/551 pág. 2.

16. Ídem. 
Por lo que entonces, para la doctrina en contra del matrimonio entre personas del mismo sexo se derivaría que el ius connubii no es más que una consagración de carácter natural debido a que el matrimonio, desde siempre, y en sus aspectos esenciales, corresponde a un vínculo entre una mujer y un hombre, por lo que toda forma de entendimiento distinto simplemente no sería un matrimonio.

La cuestión será entonces establecer cuál es la razón que vincula la naturaleza del matrimonio con la heterosexualidad y cómo es que, desde una perspectiva antropológica, sólo se permite un matrimonio entre un hombre y una mujer.

\subsection{La naturaleza del matrimonio: entre un hombre y una mujer}

Si el ius connubii es un derecho esencial para contraer matrimonio, éste debiese estar reconocido en nuestro ordenamiento jurídico para todas las personas sin importar sexo, nacionalidad, color o raza. A pesar de ello, los homosexuales no pueden contraer matrimonio en Chile. El argumento es que el matrimonio es una institución en donde la heterosexualidad forma parte de su naturaleza, por lo que si existe la homosexualidad en los contrayentes no podemos hablar de matrimonio sino de otra institución jurídica, mas nunca de matrimonio ${ }^{17}$. Entonces, ¿es posible entender la palabra 'matrimonio' comprehenda la naturaleza total y completa de este fenómeno jurídico excluyendo la posibilidad de dinamismo en cuánto a sus contrayentes?

La naturaleza heterosexual del matrimonio se vincula con la tradición iusnaturalista del derecho. En ella se señala que la heterosexualidad corresponde a una concordancia con los elementos antropológicos del ser humano debido a que siempre el matrimonio ha sido la selección del modelo de la relación unitiva y procreativa entre varón y mujer, por lo que finalmente el matrimonio seguiría a la persona humana ${ }^{18}$. En base a este modelo antropológico se erige un

17. En este sentido véase BRITO GUZMÁN, Alejandro: "La especificidad del matrimonio entre los otros tipos de unión sexual” En: Vidal Olivares, Álvaro. Ob. cit. Pág. 35.

18. HERVADA, Javier: "Una Caro. Escritos sobre el matrimonio" En: Viladrich, Pedro Juan: "El Modelo Antropológico del Matrimonio Ediciones". Madrid, Ediciones RIALP S.A., 2001. Pág. 55.

Facultad de Derecho y Ciencias Sociales - Universidad de Valparaíso - Chile 
ordenamiento institucional sobre la esencia y finalidad de la sexualidad humana que son "el bien conyugal y la procreación y educación de los hijos como finalidad específica de la unión conyugal" ${ }^{\text {. A }}$. Así el matrimonio sería una "recta ordenación de la secuencia de la sexualidad humana (...) el matrimonio es en sí mismo una correcta disposición —una asociación armónica, verdadera y buena - entre los elementos antropológicos esenciales de la sexualidad humana" ${ }^{20}$.

Siguiendo con esta idea, esto no debe leerse como la simple idea de reducir a una necesidad de supervivencia de la especie, sino como una concepción del ser humano como sujeto de entendimiento racional y voluntad libre ${ }^{21}$. VILADRICH sugiere distinguir que el matrimonio no se produce entre macho y hembra sino entre varón y mujer: "la unión entre varón y mujer contiene una ordenación espiritualizadora - personalizante - de la mera inclinación sexual corpórea, la cual expresamos en la noción y en la experiencia de la íntima compañía y amor conyugal"22. Así el cuerpo (genitales) y el alma no pueden separarse para amar y procrear, debido a que el ser humano es una persona corpórea, cuerpo y alma juntos, por lo que separar la sexualidad, procreación y amor (lo espiritual) es ir contra de la concepción antropológica del ser humano. Es por eso que el amor sería la expresión de la materialización de los seres humanos que tienden a la inclinatio

19. VILADRICH, Pedro Juan: Ob. cit. Pág. 58.

20. Ídem.

21. Cabe destacar que la idea de procreación en su sentido de "supervivencia de la especie" también ha sido uno de los principales argumentos para defender la prohibición del matrimonio entre personas del mismo sexo. En este sentido: "Una cosa es que se les reconozca el ius conubii a los impotentes y a los estériles, y otra cosa es que la regulación del matrimonio no presuponga y opere sobre la base del modelo matrimonial como una unión estable entre un hombre y una mujer. Todo lo expuesto no es arbitrario, sino que responde a la idea de asegurar la estabilidad social y el recambio y educación de las generaciones". En: MEDINA, Graciela: "Los homosexuales y el derecho a contraer matrimonio", Buenos Aires, Rubinzal-culzoni editores, 2001. Pág. 267.

22. VILADRICH. Ob. cit. Pág. 62.

Revista de Ciencias Sociales - Número 66 (2015) - Universidad de Valparáíso - ISSN 0716-7725-Valparaíso, Chile 
naturalis, que no es sino la inclinación del buen y verdadero amor sexual entre varón y mujer que establece una asociación natural entre esta inclinación amorosa y la unión conyugal; que culminaría con la procreación $^{23}$.

Siguiendo la visión de VILADRICH, el matrimonio correspondería a una idea de consagrar al ser humano como un ser dotado de voluntad racional y capacitado para amar. Aquí el amor tendería a su naturaleza, que no es sino la inclinación de complementariedad entre hombre y mujer de sentirse atraídos sexualmente vía alma (amor) y vía cuerpo (sexo). El matrimonio, entonces, debe necesariamente verse como una función procreadora - debido a que la complementariedad es la razón de amar y procrear. Más aún, para el autor...

"esta inclinación de la unión conyugal — que es unión de amora engendrar la vida la tiene el amor porque, de un lado, engendrarse en la verdad, bondad y belleza es esencia del amor mismo de la pareja y, de otro, porque engendrar el fruto que manifiesta ese amor y lo objetiva no puede tener otro mejor paradigma de excelencia que otro nuevo ser personal, el hijo, a través, del cual ambos expresan una de las realidades más consistentes de la verdad del amor, que es $<<$ dar vida $>>{ }^{24}$.

23. Esta visión si bien es cierto que existe ya en la era clásica, no es posible entenderla como la única. Explica FOUCAULT: "ser casado significa aquí ante todo ser jefe de familia, tener una autoridad, ejercer un poder que tiene en la 'casa' su lugar de aplicación y sostener las obligaciones respectiva que inciden sobre su reputación de ciudadano". En FOUCAULT, Michel: "La historia de la sexualidad. Tomo II: El uso de los placeres", Madrid, Siglo XXI, 2006. Págs. 166-167. Además véase un análisis entero de la visión griega del matrimonio en Ibíd. Págs. 157 -167 o de la visión (religiosa) del matrimonio en los inicios del mundo occidental en DE COULANGES, Fustel: "La Ciudad Antigua”, Buenos Aires, Emece editores, 1945. Págs. 107-113.

24. VILADRICH, Pedro: Ob. Cit. Pág. 102. Aquí la particularidad de la visión es que la procreación emana de la naturaleza humana y el "amor". En este sentido iría en contra de la idea de oikos, estudiada en Foucault, en cuanto la procreación sería para efectos de seguir los negocios familiares o bien, como señala De Coulanges, seguir las tradiciones religiosas. Señala De Coulanges: "El matrimonio era, pues, obligatorio. No tenía por fin el placer; su objeto principal no consistía en la unión de dos seres que se agradaban y querían asociarse para la dicha o las penas de la vida. El efecto del matrimonio, a los ojos de la religión y de las leyes, era unir a dos seres en un mismo culto doméstico para hacer nacer a un tercero que fuese apto para continuar este culto". En: De Coulanges, Fustel. Ob. cit. Pág. 116.

Facultad de Derecho y Ciencias Sociales - Universidad de Valparaíso - Chile 
Esta es (una de) la(s) idea(s) que está detrás de la negación a los homosexuales a contraer matrimonio. A la luz de los principios naturales del matrimonio, la homosexualidad, en una relación marital, no tiene sentido (no procrean porque no poseen el inclinatio naturalis, por lo que no pueden amar como aman dos cónyuges heterosexuales), por tanto, al Estado no le interesaría regularla.

Sintetizando, me gustaría rescatar dos argumentos de carácter jurídico que establecen la imposibilidad absoluta de que pueda existir el matrimonio homosexual:

1. Se aleja de estructura natural del matrimonio y la familia: "el carácter antinatural (sin dar a esta expresión contenido moral peyorativo alguno: es puramente descriptivo) de este tipo de uniones, que contradicen objetivamente el sentido - finalidad - natural de la diferenciación y complementariedad sexual: masculinidad y feminidad encuentran su sentido biológico en su respectiva complementariedad, y la procreación de nuevos seres humanos que sigue de su unión. Las prácticas homosexuales contradicen objetivamente, por su misma naturaleza, esa realidad biológica" 25 .

2. No existe la voluntad conyugal: "su contenido contradice objetivamente un elemento estructural natural del matrimonio, como es la heterosexualidad. Esa voluntad de los convivientes homosexuales, no se apoya, ni objetivamente en la estructura natural esencial del matrimonio y la familia, ni subjetivamente en la existencia de una voluntad susceptible de ser calificada como conyugal (es decir, cuyo contenido sea establecer una relación de carácter matrimonial) capaz de fundar un vínculo de carácter matrimonial”26.

25. MARTÍNEZ DE AGUIRRE, Carlos. "Diagnóstico sobre el Derecho de Familia”, Madrid, España, Ediciones RIALP S.A., 1996. Pág. 162.

26. Ibíd. Págs. 166-167.

Revista de Ciencias Sociales - Número 66 (2015) - Universidad de Valparáíso - ISSN 0716-7725-Valparáiso, Chile 
Cabe aclarar que la idea de procreación se establece aquí no como una idea circunstancial sino más bien como una institución, con independencia de que en el caso concreto se llegue a tener hijos, ello debido a la idea de que el matrimonio es la mejor vía para poder tener y criar hijos. Es por esto que se permitiría que personas estériles, viejas o aquellas que simplemente no pretendan tener hijos se casen, porque no obstaría el argumento de la procreación, debido a que estos casos son específicos y excepcionales. En definitiva, la regulación del matrimonio no se rige por las excepciones sino por principios ${ }^{27}$.

Siguiendo el argumento en contra del matrimonio igualitario, pero desde otra perspectiva, es que habrá que distinguir entre las reformas accidentales del matrimonio y las reformas esenciales. Es decir las reformas del matrimonio deben observarse desde una perspectiva jurídica como cualquier otra institución modificada por el legislador. Así "históricamente, en el derecho occidental (derecho canónico originalmente y luego el secular), y culturalmente al matrimonio le ha sido atribuido la caracterización de tres bondades, procreación (o al menos abiertos a tal), fidelidad y compromiso por toda la vida" ${ }^{28}$. Y aquello, establece el autor, se puede observar en que "ha habido sólo dos significantes cambios en los componentes esenciales o definitorios del matrimonio en los últimos 200 años [en EE.UU], y quizás en los últimos 2000 años en el mundo occidental" ${ }^{\text {. }}$. A su vez en el derecho

27. Véase MEDINA, Graciela: Ob. cit. Págs. 264-268. Este argumento podría tomarse a la inversa para defender el matrimonio entre personas del mismo sexo, en cuanto ¿́por qué no también regular las excepciones del matrimonio que implican las parejas del mismo sexo?

28. WARDLE, Lynn: "What is marriage?” [en línea] en Whittier Journal of Child and Familiy advocacy Vol. 6:1, 2006. [consultado el 20 de abril de 2015] http:/ /heinonline.org/HOL/Page?handle $=$ hein.journals/wjcfad6\&div $=7 \&$ collection $=$ journals\&set_as_cursor $=0 \&$ men_tab $=$ srchresults\&terms $=$ What $\mid$ is $\mid$ marriage? \&type $=$ matchall pág. 79.

29. Ídem. El agregado es nuestro. En este sentido ya hemos esbozado la falacia de este argumento, en cuanto las múltiples modificaciones del matrimonio en la historia. véase FOUCAULT, Michel. Ob. cit. Págs. 157-184.

Facultad de Derecho y Ciencias Sociales - Universidad de Valparaíso - Chile 
comparado sólo el 3\% (Holanda, Bélgica, España, Canadá y Sudáfrica ${ }^{30}$ ) acepta el matrimonio homosexual. Estableciendo que la idea del matrimonio homosexual es reciente y limitada en su aceptación en el campo global por lo que no se sabe si será una redefinición a gran escala o bien sólo una tendencia política que se esfumará con el tiempo ${ }^{31}$. Por lo que la naturaleza del matrimonio, que está desde tiempos bíblicos — señala el autor - afectará la definición misma de matrimonio.

En Chile los argumentos en contra de un matrimonio igualitario corresponden, similarmente, a las razones esgrimidas hasta acá. Por lo que daré una breve explicación de los argumentos de autores chilenos que están contra el matrimonio entre personas del mismo sexo dando referencia explícita a los razonamientos iusnaturales que se han mencionado.

\subsection{El matrimonio es entre hombre y mujer por su finalidad, la procreación}

Aquí se incorpora principalmente la idea de que la finalidad del matrimonio corresponde a la institución familiar por excelencia de generar descendencia. En este sentido se expresa Rodríguez Grez señalando que tal finalidad está amparada por nuestra Constitución:

"El matrimonio en función de sus fines en la Constitución Política de la República, sólo es concebible entre un hombre y una mujer. La Carta Política es clara a este respecto. La familia es un "cuerpo social intermedio" a través del cual se organiza y estructura la sociedad. La protección que se brinda en el artículo 1 inciso $2^{\circ}$ de dicho estatuto fundamental, tiene por objeto 'cumplir sus fines específicos' (...) nadie podría desconocer que dichos fines específicos están señalados en el artículo 102 del Código Civil, desde hace más de 150 años (...) El matrimonio tiene tres fines esenciales; la comunidad de vida entre marido y mujer (vivir juntos), procreación y auxilio mutuo. Si por

30. En el argumento cabe añadir algunos Estados tales como en Estados Unidos, Argentina, Uruguay, Nueva Zelanda y Francia que suman y siguen.

31. WARDLE, Lynn. Ob. cit. Pág. 65.

Revista de Ciencias Sociales - Número 66 (2015) - Universidad de Valparáíso - ISSN 0716-7725-Valparáiso, Chile 
naturaleza es imposible que la unión entre 2 personas pueda cumplir con estos fines, no hay matrimonio ni reconocimiento ni protección constitucional ni legal”"32.

Corral, siguiendo la línea, señala que la imposibilidad de consumar el acto sexual (impotencia coeundi) en el matrimonio corresponde a una causal de inexistencia del mismo: "de la mantención de la finalidad procreativa en la definición del art.102 del Código Civil puede deducirse que la imposibilidad absoluta de consumar el matrimonio mediante la cópula sexual puede conducir a afirmar, si ya no la nulidad del matrimonio, la inexistencia del mismo. La capacidad de consumar el matrimonio se traslada, entonces, de requisito de validez del mismo a requisito de existencia" ${ }^{33}$. Por lo que la mera incapacidad de poder tener relaciones sexuales o bien la capacidad para procreación (esterilidad, falta de voluntad para tener hijos o personas ancianas que se casen, etc.) serían personas que, aunque celebren el vínculo del matrimonio, no estarían legalmente casadas bajo esta doctrina.

La misma idea también la señalan Barrientos y Novales en cuanto la expresión de "un hombre y una mujer" en el Código Civil "se manifiesta en que la unión heterosexual, supuesto que la esencia del matrimonio viene determinada por sus fines propios, dentro de los cuales se encuentra el de la procreación (...)"34 por lo que la "diversidad de sexos de los contrayentes es, pues, condición esencial del matrimonio, y esta misma nota de esencialidad es la que precisa el campo operativo del ius connubii, de modo que ante el evento de la celebración de un pretendido 'matrimonio' entre personas del mismo sexo, para la ley no

32. RODRÍGUEZ GREZ, Pablo: "Ley de Matrimonio Civil: interpretación, efectos e insuficiencias”. En: “Actualidad jurídica”, Santiago de Chile, Universidad del Desarrollo, No 20 , 2009, pág. 440.

33. CORRAL TALCIANI, Hernán: "Sentido y Alcance de la definición de matrimonio del Art. 102 del Código Civil, después de la introducción del divorcio vincular por la ley 19.947, de 2004”. En: "Revista Chilena de Derecho". Santiago, Chile, vol. $36 \mathrm{~N}^{\circ} 1,2009$, pág. 71.

34. BARRIENTOS GRANDON, Javier y NOVALES ALQUÉZAR, Aránzazu: Ob. cit. Pág. 187.

Facultad de Derecho y Ciencias Sociales - Universidad de Valparaíso - Chile 
es matrimonio, pues tal acto no produce efecto alguno (...)"35. Por lo que Barrientos cree que la diversidad de sexos corresponde a la esencialidad del matrimonio.

Del Picó también adhiere a la idea iusnaturalista de complementariedad entre hombre y mujer. En este sentido el autor señala que en el artículo 102 del Código Civil "en tanto con las características y finalidades previstas en la norma, se generan las condiciones óptimas para facilitar la procreación, unida indisolublemente al propósito de asegurar la reproducción de la especie humana" ${ }^{36}$. Así del Picó se acerca más a los principios iusnaturalistas del matrimonio atribuyéndole la heterosexualidad de éste a la concepción antropológica de Villadrich del ser humano, estableciendo que "la complementariedad de los sexos como finalidad en sí misma, es el motivo principal del carácter exclusivamente heterosexual de la institución matrimonial civil, sin perjuicio del fundamento de carácter religioso o moral que informa el contenido de la norma jurídica (...)" ${ }^{37}$. Concluyendo que "la heterosexualidad, por tanto, constituye un fundamento a la base antropológica del matrimonio, en que se deben considerar como principios la diversidad de la modalización sexual de la persona humana, la complementariedad de tal diferenciación y la inclinación natural de los sexos entre sí en orden a la generación”38; por lo que Del Picó también sería de aquellos autores que ve en el matrimonio mismo, por su base antropológica iusnaturalista, como esencial la heterosexualidad en la relación marital.

Todos los autores señalados establecen que la inexistencia del matrimonio entre personas del mismo sexo estaría dada por la imposibilidad de las parejas homosexuales a procrear. Es decir, establecen que el matrimonio es una institución que promueve y busca la procreación ora para la continuación de la especie humana ora para

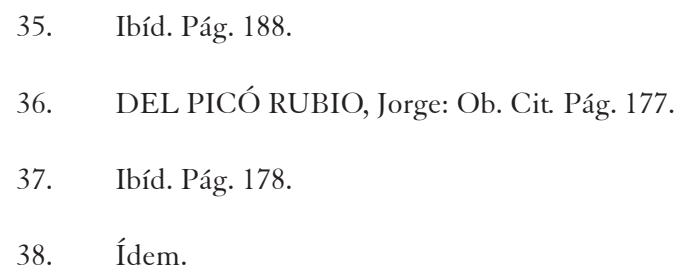


seguir la concepción antropológica del ser humano (una complementariedad del hombre con la mujer). Así la procreación se ve como un fundamento básico para la institución del matrimonio y por ello se estaría a favor de la inexistencia (al menos desde la perspectiva de Corral) de todos aquellos matrimonios en donde no existe posibilidad de procrear: ancianos, personas con imposibilidad de tener relaciones sexuales (impotencia coeundi) y personas que no pretenden tener relaciones sexuales o hijos.

Surge entonces la duda ¿es posible penalizar a personas en un Estado de Derecho, que consagra personas libres e iguales en dignidad y derechos, condenándolas a no poseer la misma capacidad jurídica - es decir impedirles contraer matrimonio- por su incapacidad o negación a generar descendencia? La cuestión cabe verla a la luz de nuestra Constitución.

\section{Respuesta a la luz de principios constitucionales de la negación del matrimonio entre personas del mismo sexo}

El quid del asunto está en cuál es la naturaleza del matrimonio y si es que aquella la podemos establecer como "la capacidad de

procrear". Por lo que antes de entrar en ella cabe mencionar que la idea de que los homosexuales no puedan contraer matrimonio en Chile consiste en una penalidad (una sanción o prohibición, una coacción a su libertad): el que a una persona, libre e igual en derecho, sólo por su orientación sexual se le impida contraer matrimonio, corresponde a un detrimento a su capacidad jurídica en asuntos civiles violando así la igualdad ante la ley, la igualdad en derechos, etc.; por su homosexualidad se le impide suscribir contratos, controlar sus bienes a su voluntad, acceder a beneficios legales y/o tributarios. La excusa es que el matrimonio, en su naturaleza, no concibe ser celebrado entre dos personas del mismo sexo; la razón: imposibilidad de cumplir su finalidad, ¿̇cuál? procrear.

La idea de la procreación - y el ius conubii también — se consagra desde una perspectiva iusnaturalista otorgándole una connotación de expresión de amor $^{39}$ al acto sexual. Esto implica no entender al derecho,

39. VÉASE BRUDAGE, James. "La Ley, el sexo y la sociedad cristiana en la Europa medieval”, México DF, Fondo de Cultura Económica, 2000. En:

Facultad de Derecho y Ciencias Sociales - Universidad de Valparaíso - Chile 
a través del matrimonio, como un elemento sociointegrador en el cual puedan las personas desenvolverse libremente como ciudadanos, debido a que la concepción de mundo y la materialización de la noción antropológica que los iusnaturalistas persiguen, responden a una visión particular del ser humano - aquél que debe complementarse hombre con mujer y buscar el amor real en el otro sexo- descartando una visión que contemple distintas respuestas a la problemática existencial de las parejas.

Los argumentos que se utilizan para establecer la naturaleza del matrimonio en virtud de una concepción iusnaturalista de éste, deben ser rechazados; esto porque el marco de discusión del matrimonio entre personas del mismo sexo es un ordenamiento jurídico que se entiende a sí misma como secular y laica. Además, pretende tener un sesgo de imparcialidad para la consecución de una teoría de la justicia. Rawls señala que "las únicas doctrinas comprensivas que se apartan de la razón pública son aquellas que no pueden servir de soporte a un equilibrio razonable de valores políticos" ${ }^{\prime 0}$. Y es precisamente lo que sucede acá: por entender al matrimonio desde una perspectiva natural se rompe la idea de una consagración de igualdad de derechos cuando se le impide a personas del mismo sexo contraer matrimonio.

La negación al matrimonio homosexual está basada en comprender al ser humano como poseedor de un cuasideber de complementariedad entre hombres y mujeres, estableciendo que el matrimonio es la consagración de la pareja a través del cuerpo (inclinatio naturalis) y el alma (a través del amor). Por tanto sólo aquella manifestación de amor ('la verdadera') conllevaría, a través del acto sexual, la procreación. Este argumento debe ser rechazado por arbitrario. Ello debido a que la concepción de persona que se maneja en un sistema constitucional, presenta a los seres humanos con capacidad de razonar

"Igualdad y Matrimonio homosexual frente al Derecho Constitucional" de GALLEGO SAADE, Javier (Inédito). Agradezco a Javier la amabilidad de poder revisar su trabajo en desarrollo para poder sacar algunas ideas que complementan mi trabajo.

40. RAWLS, John: “Liberalismo Político”, México D.F., Fondo de Cultura Económica, 2006. Pág. 230.

Revista de Ciencias Sociales - Número 66 (2015) - Universidad de Valparáíso - ISSN 0716-7725-Valparaíso, Chile 
y proporcionar sus propias decisiones sobre qué y quiénes deben ser su 'complemento' y a 'quién' deciden amar. Rawls señala: “los ciudadanos son libres en la medida en que conciben a sí mismos y unos a otros como poseedores de la capacidad moral para tener una concepción del bien (...) capaces de revisar y cambiar su concepción, fundados en elementos razonables y racionales, y pueden hacer esto si así lo desean" ${ }^{\prime 1}$. Por lo que la concepción antropológica del ser humano prescinde de la posibilidad de que las personas puedan decidir por ellos mismos sus propias concepciones del bien, coartando lo que Rawls llama "su identidad no institucional, o moral" ${ }^{2}$. Entonces, una institución que rechaza la posibilidad de que las personas escojan racional y libremente a quién amar y quién es su complemento, negaría la esfera política del individuo en cuanto no podría desenvolverse en un marco jurídico imparcial ergo justo. Por lo que el argumento en cuestión corresponde más bien a uno de tinte moral, fundado en doctrinas de carácter sectario que no responden a una sociedad pluralista ${ }^{43}$.

El otro argumento a responder es a la excesiva —a mi juiciopreocupación por la procreación. Como bien vimos, la idea detrás de la negación de un matrimonio homosexual está en que el matrimonio produce las condiciones óptimas para la procreación; por tanto, sin procreación no hay matrimonio.

Entramos aquí al meollo del asunto: ¿es posible penalizar a una persona por no poseer la capacidad para poder procrear, negándole la capacidad jurídica de contraer matrimonio, como sostiene Corral? Parece un exceso. La idea de Corral se aleja de la realidad, porque en la práctica se haría imposible impedir o declarar inexistentes matrimonios en los cuales las parejas tienen imposibilidad de procrear. Nunca ha sido la intención, al menos desde la aprobación de la LMC,

41. Ibíd. Págs. 51-52.

42. Ídem.

43. NUSSBAUM, Martha: "Aright to marry? "Same-sex marriage and Constitutional law”, [en línea] Dissent, Vol. 56, No 3, 2009. [consultado el 21 de abril de 2015] http://www.sjsu.edu/people/albert.filice/courses/phil61/s6/Marta\%20 Nussbaum.pdf pág. 5.

Facultad de Derecho y Ciencias Sociales - Universidad de Valparaíso - Chile 
declarar como inexistentes los matrimonios en los cuales a los cónyuges no les sea posible la procreación o bien tener relaciones sexuales. Es más, la idea de la nulidad ante la imposibilidad de "procrear" ya era mal vista por nuestra jurisprudencia por lo que no se aceptaba como causal de nulidad ${ }^{44}$, señala la Corte de Apelaciones de Santiago:

"el fin de la procreación puede no existir en la mente de los contrayentes y en la realidad física de ellos, especialmente cuando se trata de matrimonios de personas de edad avanzada, sin que por ello se haya creado una causal de nulidad por impotencia; pensar lo contrario sería sostener la prohibición legal de contraer matrimonio a los ancianos, lo que no está ni ha estado en el ánimo del legislador" ${ }^{45}$.

Por tanto la procreación puede ser un interés del matrimonio pero no una causal de inexistencia ni de nulidad del mismo, debido a que el matrimonio civil no tiene como único fin la procreación ni el acto sexual ${ }^{46}$. En este sentido "la creencia que el sólo o primer propósito del matrimonio es concebir y criar hijos deriva de las enseñanzas religión cristiana. Sin embargo, el decreto del segundo concilio del Vaticano, por ejemplo, no promulga más este exclusivo propósito del matrimonio" ${ }^{47}$ así podría verse en el canon 1084 del Código Canónico de 1983 § 3, norma que dispone expresamente que "la esterilidad no prohíbe ni dirime el matrimonio".

44. Artículo $4 \mathrm{~N}^{\mathrm{o}} 3$ de la Antigua Ley de Matrimonio Civil.

45. C. Santiago, 1 de julio 1958. R., t. 55, sec. $2^{\text {a }}$, pág. 54.

46. Igualmente la doctrina ha entendido que la infertilidad podría alzarse como fundamento de nulidad matrimonial consagrado en la letra b) del artículo 44 de la LMC, cuando la falta de consentimiento libre y espontáneo fuere consecuencia de un error recaído en una cualidad personal del otro cónyuge (Art. 8 número 2 LMC) que, precisamente, consistiera en su "fertilidad" si ella ha sido determinante para prestar el consentimiento matrimonial, porque quién ha errado tenía en cuenta el fin de procreación. Aquí, entonces, no sería la infertilidad en sí misma la razón de nulidad sino el error esencial en la persona. Véase BARRIENTOS y NOVALES: Ob. cit. Pág. 174.

47. KINDREGAN, Charles: "Religion polygamy and non-traditional families: despair views on the evolution of marriage in history and in the debate over samesex unions", Suffolk University Law Review, Vol. XLI: 1, 2007. Pág. 44.

Revista de Ciencias Sociales - Número 66 (2015) - Universidad de Valparáíso - ISSN 0716-7725-Valparaíso, Chile 
Es verdad que desde una perspectiva natural, basada en su particular concepción antropológica, puede ser la procreación y la crianza de los hijos la finalidad principal del matrimonio. Pero aquello no se condice en un Estado de derecho democrático. Las relaciones entre las personas deben observarse en virtud de los principios constitucionales que rigen nuestra sociedad, por lo que el matrimonio debiera leerse en una perspectiva dinámica capaz de aprehender la evolución de la sociedad y los principios constitucionales, que son la igualdad entre los ciudadanos y la no interferencia en la vida privada de los mismos ${ }^{48}$. Por ello se hace relevante destacar que en el matrimonio entre personas del mismo sexo confluyen los dos componentes más significantes del matrimonio tradicional: la intimidad y la estabilidad ${ }^{49}$, por lo que a los ojos de la Constitución no existiría impedimento alguno para poder llevar a cabo el matrimonio si es que ni la procreación, ni la consumación del matrimonio se logran.

Cabe por último argumentar por qué no sería preocupación del Estado de Derecho el que la sexualidad y la procreación sea interés del matrimonio como institución. Tal idea debe analizarse desde la óptica del derecho a la intimidad y el derecho al libre desarrollo de la personalidad.

En la preocupación por la procreación, subyace la idea de cómo se relacionan sexualmente las parejas casadas. Así, cuando el derecho civil se concentra en cómo se debe llevar a cabo la sexualidad en una pareja (casada), se produce una intervención del Estado en la esfera íntima de las personas vulnerando el artículo $19 \mathrm{~N}^{\circ} 4$ de la Constitución. El fomentar la 'reproducción de la especie humana' en 'condiciones coherentes a nuestra sociedad' peca de preocuparse en uno de los asuntos más íntimos de la persona humana, la sexualidad. El prohibir el

48. Ídem.

49. VV. AA: "The constitution and the family", Harvard Law Review, vol. 93-1156 (1980) pág. 1285. Esta posición por otro lado no es pacífica, ello debido a que existen autores que consagran el affectio maritalis como el núcleo del matrimonio, como lo señala MERIN, Youval: "en el siglo XX el amor se ha convertido en el objetivo y razón, sino la más importante, la única dentro del matrimonio", "Equality for samesex couples”. Chicago, The University of Chicago Press, 2002. Pág. 28.

Facultad de Derecho y Ciencias Sociales - Universidad de Valparaíso - Chile 
matrimonio debido a que no se cumple la finalidad de la procreación es preocuparse de cómo se va a llevar a cabo la vida sexual de una pareja que contrae matrimonio (es decir si tendrán o no relaciones sexuales, de qué forma tendrán relaciones sexuales, si pretenden o no tener hijos, etc.) y aquello es una vulneración grosera al derecho de la intimidad. $\mathrm{Al}$ legislador no puede importarle si la pareja que contrae matrimonio tiene impotencia generandi o couendi, si hay pretensión de tener hijos o no, si consuman el matrimonio o no, debido a que aquello recae necesariamente en la esfera de privacidad de las personas y no en el Estado. Por tanto el prohibir el matrimonio debido a que no se cumple la finalidad de procrear es extralimitar la actuación del Estado e insertar un germen de inconstitucional en la actuación del mismo que no debería permitirse. La preocupación por la procreación puede importarle al Estado pero no al punto de impedir que dos personas puedan generar un contrato o una familia; la preocupación del Estado por la procreación debe ser siempre resguardando el derecho a la intimidad de las personas y los derechos fundamentales.

Así la preocupación excesiva por la procreación genera una inconstitucionalidad en la figura del matrimonio. La idea de resguardar la procreación en el matrimonio (este es el argumento en contra de la parejas homosexuales) es una idea heredada del derecho natural que sólo tiene sentido en virtud de la concepción antropológica católica del mismo y no en la concepción política de persona que Rawls señala. Así, aunque fuese cierto que el matrimonio trata de proteger la supervivencia del ser humano, el Estado no puede violar derechos fundamentales para garantizar aquello. La idea de una inspección sobre quién puede o quién no puede tener hijos es excesiva y arbitraria; que el Estado se preocupe de la procreación a través de un scanner sobre la capacidad sexual y engendradora de los ciudadanos casados es excesivo, no siendo coherente con un Estado de Derecho democrático.

\section{Conclusión}

Dentro del trabajo se realizó un análisis al matrimonio desde un punto de vista filosófico y jurídico que, a su vez, se separó en dos sentidos: en virtud de su naturaleza jurídica y como una institución civil subsumida a la Constitución.

Revista de Ciencias Sociales - Número 66 (2015) - Universidad de Valparáíso - ISSN 0716-7725-Valparáiso, Chile 
Para los juristas en contra del matrimonio entre personas del mismo sexo, éste se configura como un derecho natural, a través del ius connubi que no es más que el derecho pre-estatal de las personas a casarse. Esto nos hace preguntarnos ¿qué clase de elementos hacen entender el matrimonio como natural? El ius conubii emerge como un derecho previo al Estado y revelador en torno a la naturaleza inmutable del mismo matrimonio: al ser un derecho esencial y previo al Estado, en caso de cambiar el matrimonio, éste deja de llamarse matrimonio pasando a ser otra cosa (pero no matrimonio). Además este está configurado no en torno a personas sino al hombre y la mujer (como, por ejemplo, lo señala el artículo 32 de la Constitución española). Esto es determinante debido a que sólo un hombre y una mujer lo pueden contraer con el afán institucional de procrear. Sin embargo el derecho supraconstitucional del ius connubi cae en una paradoja: sería un derecho natural pre-estatal, sin embargo no se entiende de qué forma sería posible contraer matrimonio en esa etapa previa al Estado, debido a que el matrimonio es una institución que se enmarca dentro de un Estado, por tanto no existiría matrimonio en este plano de la argumentación.

A pesar de las incongruencias lógicas en que cae el ius connubi, ha estado siempre latente el concepto de la procreación como un elemento natural del matrimonio. Aquél elemento ha sido constante y permanente a lo largo del tiempo a pesar de las razones que lo han inspirado. Entonces ¿̇es posible entender la procreación como elemento esencial del matrimonio? A nuestro entender no. Ello debido a que la fundamentación del matrimonio se ha basado principalmente en una concepción católica de persona y no política de la misma (Rawls), por lo que no se respeta un derecho básico de las personas: el que ellos mismos puedan determinar sus propias concepciones del bien. Además la procreación como elemento determinante se inspira en una concepción natural del matrimonio, el amor. La complementariedad del ser humano es un elemento que no puede trasladarse a la esfera pública porque no todos adhieren a tales concepciones de amor, ello debido a la libertad de conciencia y la libertad de desarrollar sus propios proyectos de vida. Por tanto no podemos entender la heterosexualidad como un aspecto natural del matrimonio porque deriva de una

Facultad de Derecho y Ciencias Sociales - Universidad de Valparaíso - Chile 
concepción arbitraria de persona que impide a los seres humanos insertos en el Estado de Derecho- decidir por ellos mismos quiénes son su complementariedad y a quiénes deciden amar. Es decir, la heterosexualidad, como requisito natural del matrimonio, no supera el estándar constitucional que requiere una institución jurídica como el matrimonio en el marco de un Estado de derecho democrático.

Por último la procreación tiene dos problemas relevantes: (1) no se entiende cómo se puede reglamentar y sancionar todas aquellas parejas que no pretenden o no pueden tener hijos. Así los ancianos, los estériles o simplemente los que no quieran tener hijos serán privados injustamente de una capacidad jurídica. Y (2) que el Estado no puede inmiscuirse ex ante en la procreación porque eso es preocuparse de uno de los aspectos más íntimos de las personas: la sexualidad. Por tanto en la medida de que al Estado le preocupe cómo se lleva a cabo la sexualidad, se estaría vulnerando el derecho de intimidad resguardado por nuestra Constitución. Por ello parece sumamente incorrecto penalizar a las personas por no querer o no poder tener descendencia, a no tener la misma capacidad jurídica que cualquier otra persona dentro de un Estado de Derecho.

Es por ello que no existe ninguna razón desde la óptica propia del matrimonio para impedir que dos personas del mismo sexo puedan casarse.

\section{Bibliografía consultada}

ALDUNATE LIZANA, Eduardo: "El derecho esencial a contraer matrimonio". En: Vidal Olivares, A. (coord.) El nuevo derecho chileno del matrimonio (Ley No 19.947 de 2004)" Santiago de Chile, Editorial Jurídica de Chile, 2006. Pp. 39-48

ASÚA GONZÁLEZ, Clara: "Matrimonio entre personas del mismo sexo. Reflexiones al hijo de la ley 13/2005". En: Revista "Nuevas familias y principio de igualdad: un debate abierto”, colección Jornadas de Derechos Humanos No 9, San Sebastián, España, 2005. Pp. 27-50. BARRIENTOS GRANDÓN, Javier y NOVALES ALQUÉZAR, Aránzazu: "Nuevo Derecho Matrimonial chileno", $2^{\circ}$ edición, Santiago de Chile, Editorial LexisNexis, 2004. P. 472.

Revista de Ciencias Sociales - Número 66 (2015) - Universidad de Valparáíso - ISSN 0716-7725-Valparaíso, Chile 
"La inexistencia del matrimonio en el derecho chileno". En: Revista del Derecho, Vol. XIX, N², Santiago, Chile. Pp. 53-83.

BRITO GUZMÁN, Alejandro: "La especificidad del matrimonio entre los otros tipos de unión sexual". En: "El nuevo Derecho chileno

del Matrimonio" (coord. Álvaro Vidal Olivares), Santiago de Chile, Editorial Jurídica de Chile, 2006. Pp. 23-38.

BRUDAGE, James: "La Ley, el sexo y la sociedad cristiana en la Europa medieval”, México D.F., Fondo de Cultura Económica, 2000.

P. 669.

CEA EGAÑA, José Luis: "Derecho Constitucional chileno tomo I", $2^{\circ}$ edición, Santiago de Chile, Ediciones Universidad Católica de Chile, 2008. P. 580.

CORRAL TALCIANI, Hernán: "Familia sin matrimonio, ¿̇modelo alternativo o contradicción excluyente?”. En: Revista Chilena de Derecho, Santiago, Chile, 21 N $^{\circ} 2$ (1994). Pp. 245-257.

"Concepto y reconocimiento legal de la familia de hecho". En: Revista Chilena de Derecho, Santiago, Chile, 17 (s/n), 1990. Pp. 35-85.

"Ley de Divorcio. Las razones de un no". Estudios de Derecho Actual, Santiago de Chile, Universidad de los Andes, 2001. P. 212 .

"Sentido y Alcance de la definición de matrimonio del Art. 102 del Código Civil, después de la introducción del divorcio vincular por la ley 19.947, de 2004". En: "Revista Chilena de Derecho" vol. $36 \mathrm{~N}^{o}$ 1, Santiago, Chile, 2009. Pp. 51-76.

DE COULANGES, Fustel: "La Ciudad Antigua", $3^{\circ}$ Edición, Buenos Aires, Emece editores, 1945. P. 556.

DEL PICÓ RUBIO, Jorge: “Derecho matrimonial Chileno”, Santiago de Chile, Abeledo Perrot Legal Publishing, 2010. P. 459.

FOUCAULT, Michel: "La historia de la sexualidad. Tomo II: El uso P. 291. de los placeres", $30^{\circ}$ Edición, Madrid, España, Siglo XXI, 2006.

GIL DOMÍNGUEZ, Andrés: Matrimonio igualitario y derecho constitucional: ley 26.618, Buenos Aires, Argentina, Editar, 2010. P. 507.

HABERMAS, Jürgen: "Facticidad y Validez", $5^{\circ}$ edición, Madrid, España, Editorial Trotta, 2008. P. 696.

Facultad de Derecho y Ciencias Sociales - Universidad de Valparaíso - Chile 
HERNÁNDEZ PAULSEN, Gabriel: "Uniones afectivo-sexuales y matrimonios entre personas del mismo sexo", Santiago de Chile, Editorial ARCIS, 2009. P. 217.

ISLER SOTO, Erika: "Los principios de la Ley 19.947: análisis y desarrollo" [en línea]. En: Ars Boni et Aequi, 2009, [consultado el 20 de abril de 2015] http://www.ubo.cl/icsyc/wp-content/uploads/ 2011/09/4-Isler.pdf pp. 83-116.

KINDREGAN, Charles: "Religion polygamy and non-traditional families: despair views on the evolution of marriage in history and in the debate over same-sex unions" [en línea], Suffolk University Law Review, Vol. XLI: 1, 2007. [consultado el 21 de abril de 2015] http:/ /suffolklawreview.org/wp-content/uploads/2007/11/ Kindregan_Article_FINAL.pdf pp. 19-48.

NUSSBAUM, Martha: "A right to marry? "Same-sex marriage and Constitutional law", [en línea] Dissent, Vol.56, Nº 3, 2009. [consultado el 21 de abril de 2015] http://www.sjsu.edu/people/albert. filice/courses/phil61/s6/Marta\%20Nussbaum.pdf. pp. 43-55.

MARTÍNEZ DE AGUIRRE, Carlos: "Diagnóstico sobre el Derecho de Familia”, Madrid, España, Ediciones RIALP S.A., 1996. P. 226.

MEDINA, Graciela: "Los homosexuales y el derecho a contraer matrimonio", Buenos Aires, Argentina, Rubinzal-culzoni editores, 2001. P. 291.

MERIN, Youval: "Equality for same-sex couples". Chicago, The University of Chicago Press, 2002. P. 398.

RAWLS, John: "Liberalismo Político", $5^{\circ}$ edición, México D.F, Fondo de Cultura Económica, 2006. P. 440.

"Teoría de la Justicia”, $2^{\circ}$ edición, México D.F., Fondo de cultura económica, 2010. P. 560.

RODRÍGUEZ GREZ, Pablo: "Ley de Matrimonio Civil: interpretación, efectos e insuficiencias". En: "Actualidad jurídica", 20 (2009), Santiago de Chile, Universidad del Desarrollo, 2009. Pp. 365-444.

TIRAPU MARTÍNEZ, Daniel: "La cuestión no cerrada del matrimonio homosexual” [en línea]. En: Revista de Estudios jurídicos $\mathrm{N}^{\circ} 10 /$ 2010 (Segunda época) ISSN 1576-124X. Universidad de Jaén (España) [consultado 20 de abril de 2015] http://revistaselectronicas.ujaen.es/ index.php/rej/article/view/551 p. 11.

Revista de Ciencias Sociales - Número 66 (2015) - Universidad de Valparáíso - ISSN 0716-7725-Valparaíso, Chile 
TURNER SAELZER, Susan: "Tendencias constitucionales relativas a la protección de la familia”. En: Estudios de Derecho Civil IV. VI Jornadas Nacionales de Derecho Civil - Universidad Diego Portales -Olmué- 2008. PIZARRO WILSON, Carlos (Coord.)Santiago, Chile, Editorial LegalPublishing, 2009. Pp. 89-102.

VILADRICH, Pedro Juan: "El Modelo Antropológico del Matrimonio". Madrid, España, Ediciones RIALP S.A, 2001. P. 129.

VV. AA, "The constitution and the family", Harvard Law Review, vol. 93-1156 (1980). Pp. 1156-1383.

WARDLE, Lynn. "What is marriage?" [en línea]. En: Whittier Journal of Child and Familiy advocacy Vol. 6:1, 2006. [consultado el 20 de abril de 2015] http://heinonline.org/HOL/Page?handle= hein.journals/wjcfad6\&div $=7 \&$ collection $=$ journals\&set_as_cursor $=$ $0 \&$ men_tab $=$ srchresults\&terms $=$ What $\mid$ is $\mid$ marriage $?$ \&type $=$ matchall p. 54. 